\title{
Abnormal focal 99mTc-DMSA uptake in the lung - report of two cases
}

Elahe Pirayesh ${ }^{1}$, Mahasti Amoui ${ }^{1}$, Ali Asghar Halimi Asl ${ }^{2}$, Majid Assadi ${ }^{3}$

${ }^{1}$ Department of Nuclear Medicine, Shohada e Tajrish Medical center, Shahid Beheshti University of Medical Sciences, Tehran, Iran 2Department of Pediatric, Shohada e Tajrish Medical center, Shahid Beheshti University of Medical Sciences, Tehran, Iran ${ }^{3}$ The Persian Gulf Nuclear Medicine Research Center, Bushehr University of Medical Sciences, Bushehr, Iran

The author(s) declare that they have no conflict of interests.

[Received 9 VIII 2013; Accepted 7 I 2014]

\begin{abstract}
Extrarenal uptake of 99mTc-DMSA is a rare finding, which has been described in some unusual conditions as bone metastasis, aortic aneurysm and hemangioma. The purpose of this report is to present two cases of abnormal 99mTc-DMSA uptake in the lungs, which remained unexplained even after radiologic assessment.
\end{abstract}

KEY words: 99mTc-DMSA scintigraphy, extrarenal uptake, urinary infection

Nuclear Med Rev 2014; 17, 1: 35-37

\section{Introduction}

Renal scintigraphy with technetium-99m dimercaptosuccinic acid (99mTc-DMSA) is one modality used to distinguish pyelonephritis (APN) and renal parenchymal scars [1]. Extrarenal uptake of $99 \mathrm{mTc}-\mathrm{DMSA}$ is a rare finding, which has been described in some unusual conditions as bone metastasis, aortic aneurysm and hemangioma [2-6]. The purpose of this report is to present two cases of an abnormal 99mTc-DMSA uptake in the lung, which remained unexplained even after radiologic assessment.

\section{Case report}

\section{Case 1}

A 5-year-old girl suspicious for pyelonephritis was referred to our department for evaluation of renal parenchymal function by 99m-technetium-Dimercaptosuccinic acid (99mTc-DMSA). She had history of fever, abdominal pain and dysuria. She had no cough, upper respiratory infection (URI) symptoms, or rash. Past history was unremarkable and she was on no medications. A urine specimen was rather cloudy and positive for white blood cell (WBC) and leukocyte esterase. Laboratory data revealed an elevated erythrocyte sedimentation rate (ESR) and leukocytosis. Scan was obtained

Correspondence to: Majid Assadi, MD

The Persian Gulf Nuclear Medicine Research Center

The Persian Gulf Biomedical Sciences Institute

Boostan 19 Alley, Sangi Street, Bushehr, Iran

Phone: 00987712580169

Fax: 00987712541828

E-mail: assadipoya@yahoo.com, asadi@bpums.ac.ir three hours after IV injection of $74 \mathrm{MBq}(2 \mathrm{mCi}) 99 \mathrm{mTc}-\mathrm{DMSA}$ in anterior, posterior and oblique view. Right kidney revealed globally decreased radiotracer uptake, with prominent defects in both poles; suggestive of pyelonephritis. Surprisingly, there was also a focal zone of abnormal radiotracer uptake in right lung (adjacent to the hilum), which was confirmed in right lateral image (Figure 1). Following this unusual finding, chest $\mathrm{X}$ ray in anterior posterior (AP) and lateral views was done, which was unremarkable. So, chest CT scan was undertaken to exclude any space-occupying lesion. But no abnormality was found in the right lung, too (Figure 2). Radionuclide cysternography confirmed moderate urinary reflux on the right side. The patient received treatment course of proper antibiotics and then commenced on antibiotic prophylaxis. During more than 6 months follow up, the patient did not have any pulmonary problem or discomfort.

\section{Case 2}

Tc-99m DMSA renal scintigraphy was performed in a 35-year-old man, referred for the evaluation of recently detected renal failure. He had history of newly detected high serum creatinine level $(2.5 \mathrm{mg} / \mathrm{dL})$, found during evaluation for hypertension. He was a healthy man and his past medical history and routine physical examination was unremarkable. Three hours after IV injection of $185 \mathrm{MBq}(5 \mathrm{mCi})$ of freshly prepared 99mTc-DMSA, images were obtained in anterior, posterior and oblique views. Scintigram demonstrated relatively small-sized kidneys with decreased radiotracer uptake and high background activity (Figure 3). Some abnormal foci of activities were noted in both lung fields, confirmed on the SPECT study. The patient underwent chest CT, which showed no abnormality in the lungs. 


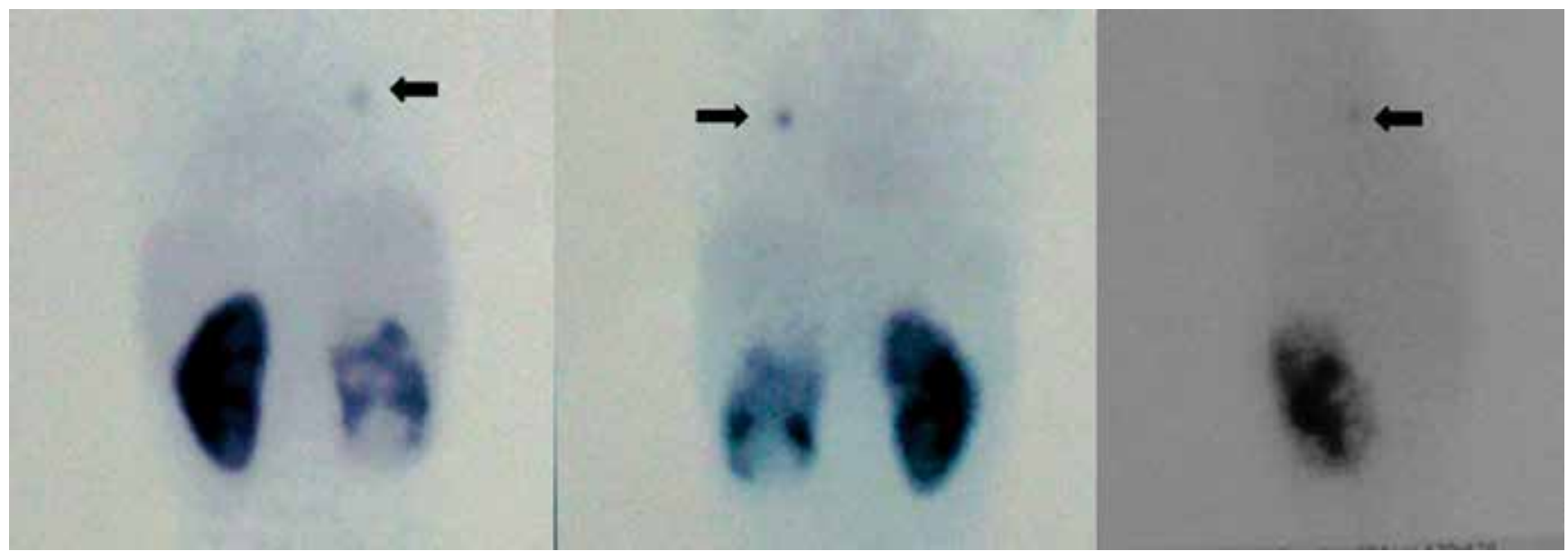

Figure 1. 99mTc-DMSA in posterior, anterior and right lateral views. Right kidney revealed globally decreased radiotracer uptake, with prominent defects in both poles; suggestive of pyelonephritis. In addition, there was a focal zone of abnormal radiotracer uptake in right lung (adjacent to the hilum)
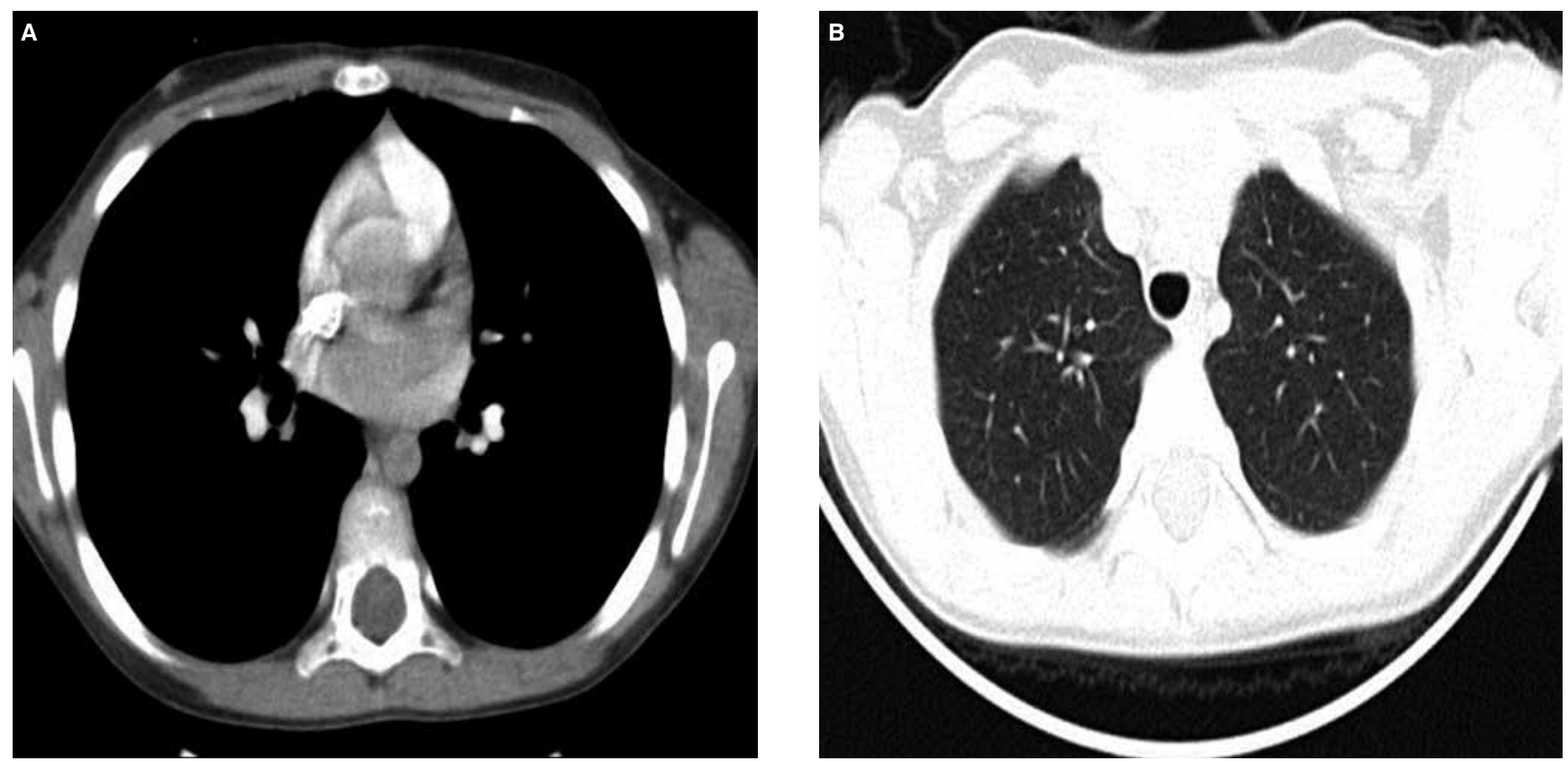

Figure 2. Normal chest CT scan (A, B)

\section{Discussion}

99mTc-DMSA renal scintigraphy is a well-accepted method for the evaluation of renal parenchymal function. Two hours after intravenous injection, more than $50 \%$ of the injected $99 \mathrm{mTc}-\mathrm{DMSA}$ is found mainly in the renal cortex, whereas there is only minimal background activity [7]. Extrarenal localization of 99mTc-DMSA is a rare finding and there are just some limited reports about abnormal uptake in splenic amyloidosis, bone metastases, renal pelvic diverticulum, infantile hemangioma and abdominal aortic aneurysm $[2,3,5,6,8,9]$. This finding has been attributed to the presence of free $99 \mathrm{mTc}$, high percentage of pentavalent DMSA (V-DMSA), hypervascularity of the lesions and high blood pool activity. Some molecular mechanisms, like active transport through the tumor cells or chelating of the tracer with a molecule within the abnormal

cell membrane or cellular compartment, has also been proposed $[3,9]$. We found just one case, reporting unexplained bilateral basal lung uptake of $99 \mathrm{mTc}-\mathrm{DMSA}$ in a patient with pulmonary edema without pleural effusion [10].

To the best of our knowledge, this is the first report describing focal uptake of $99 \mathrm{mTc}-\mathrm{DMSA}$ in the lungs. In these two patients, chest CT was normal and we could not find any anatomic explanation for the abnormal uptakes. However, in both patients some degrees of renal insufficiencies and high background activity were noted. There was also no evidence of the presence of free $99 \mathrm{mTc}$, too. So, it seems that the only cause that may play a role in the uptake of 99mTc-DMSA in the lungs is renal failure, resulted in high blood pool activity. Retention of tracer in some vessels (possibly ecstatic vessels) may lead to abnormal focal uptakes in the lungs. 
A

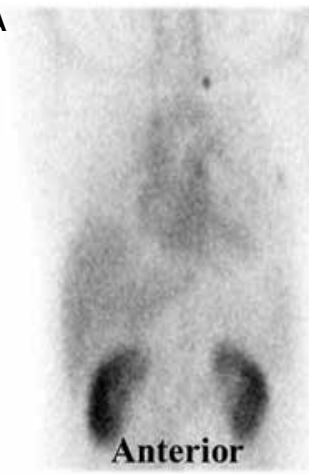

Anterior

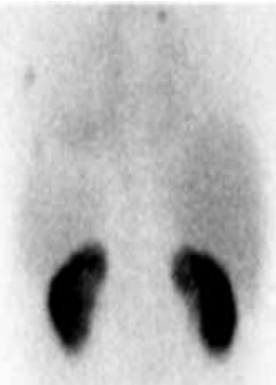

Posterior
B
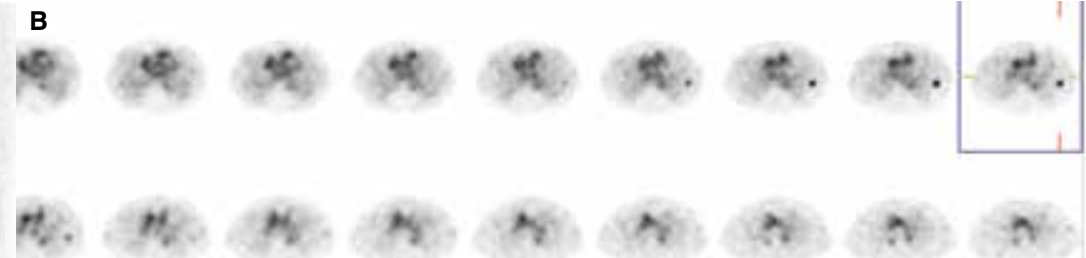

Figure 3. 99mTc-DMSA in anterior and posterior views. Scintigram demonstrated relatively smallsized kidneys with decreased radiotracer uptake and high background activity (A). Some abnormal foci of activities were noted in both lung fields (A), confirmed on the SPECT study (B)

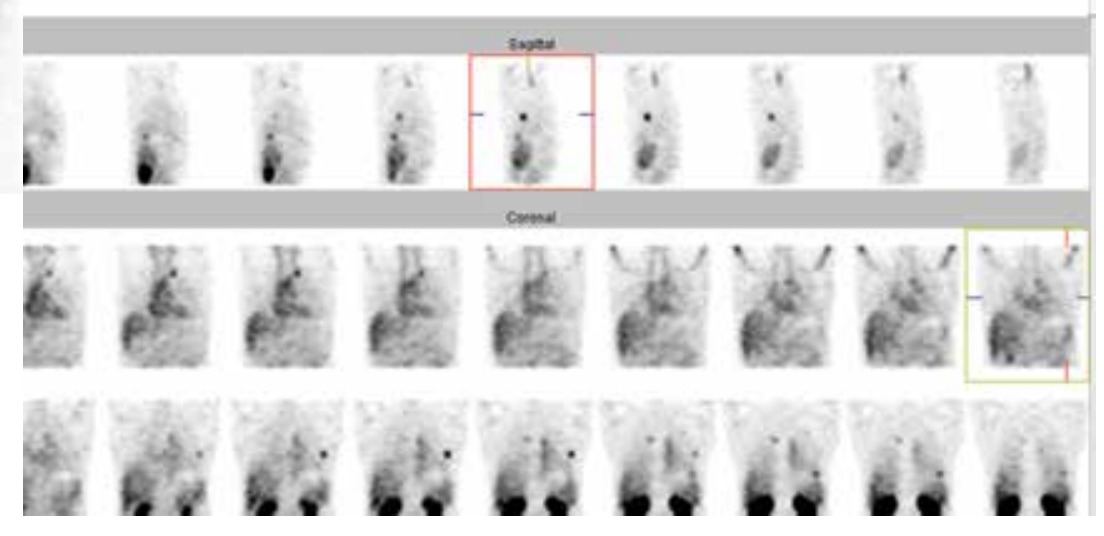

\section{References}

1. Ghasemi K, Montazeri S, Pashazadeh AM, Javadi H, Assadi M. Correlation of 99mTc-DMSA scan with radiological and laboratory examinations in childhood acute pyelonephritis: a time-series study. Int Urol Nephrol 2013.

2. Barai S, Bandopadhayaya GP, Rathi M, Singh NG. accumulation of Tc99m-DMSA-3 in the spleen in acase of multiple myeloma with associated amyloidosis. J Postgrad Med 2005; 51: 119-121.

3. Balci TA, Ciftci I, Karaoglu A. Incidental DTPA and DMSA uptake during renal scanning in unknown bone metastases. Ann Nucl Med 2006; 20: 365-369.

4. Turgut B, Erselcan T, Ozdemir S, Hasbek Z, Tosun HB, Topaktas S. A large renal pelvic diverticulum, presenting incomplete excretion during Tc-99m MAG-3 scintigraphy and tracer accumulation on Tc-99m DMSA scintigraphy; a case report Ann Nucl Med 2004; 18: 689-693.
5. Dirlik A, Ozcan Z, Sureyya O, Karapinar B, Ozyurt O, Cura A. Tc-99m DMSA Localization in Infantile Hemangioma. Clin Nucl Med 2002; 27: 225-226.

6. Raman V, Kapse N, Karugaba R et al. An Unusual Presentation of Abdominal Aortic Aneurysm on Static Renal Tc-99m DMSA Scintigraphy. Clin Nucl Med 2007; 32: 418-420.

7. Durand $E$, Prigent $A$. The basics of renal imaging and function studies. Q J Nucl Med 2002; 46: 249-267.

8. Turgut B, Erselcan T, Ozdemir S, Hasbek Z, Tosun HB, Topaktas S. A large renal pelvic diverticulum, presenting incomplete excretion during Tc-99m MAG-3 scintigraphy and tracer accumulation on Tc-99m DMSA scintigraphy; a case report. Ann Nucl Med 2004; 18: 689-693.

9. Rondogianni P, Koniaris G. Tc-99m DMSA Uptake by Metastatic Colorectal Carcinoma. Clin Nucl Med 2004; 29: 485-487.

10. Wilson FMA, Smith FW. Unexplained Technetium-99m DTPA uptake by lung. Clin Nucl Med 1987; 12: 487-488. 